\title{
The role of 18F-FDG-PET/ CT in initial staging and re-staging of head and neck cancer
}

\author{
Abdullah Demirkan ${ }^{1}$, Pelin Ozcan Kara ${ }^{2}$, Kayhan Oztürk ${ }^{3}$, Oktay Sari ${ }^{4}$, Nazim Barıs Kanat ${ }^{5}$, Izzet \\ Ozgür Ozlük ${ }^{1}$, Ahmet Kibar ${ }^{1}$ \\ 1. Department of Head and Neck Surgery, Necmettin Erbakan University, Meram Medical Faculty, Konya, Turkey. \\ 2. Department of Nuclear Medicine, Mersin University, Medical Faculty, Mersin, Turkey. 3. Department of Head and Neck \\ Surgery, Selcuk University, Selcuklu Medical Faculty, Konya, Turkey. 4. Department of Nuclear Medicine, Selcuk \\ University, Selcuklu Medical Faculty, Konya, Turkey. 5. Department of Nuclear Medicine, Cukurova University, Medical \\ Faculty, Adana, Turkey.
}

Correspondence: Pelin Ozcan Kara. Address: Mersin University, Medical Faculty, Department of Nuclear Medicine, Mersin, Turkey. E-mail: ppelinozcan@gmail.com

Received: February 7, 2014

Accepted: May 23, 2014

Online Published: July 31, 2014

DOI : $10.5430 /$ jbgc.v4n3p57

URL: http://dx.doi.org/10.5430/jbgc.v4n3p57

\section{Abstract}

The aim of this study is to have a solid basis for the effectiveness of the 18F-FDG-PET/CT imaging technique, which has known advantages for patients with head and neck cancers during staging and restaging prior to treatment and to compare this method with the corresponding clinical and radiological methods.

A total of 139 patients with squamous cell head and neck carcinoma underwent PET/CT imaging. A total of 146 PET/CT imaging was performed in all patients. PET/CT imaging performed for staging and restaging in 36 and 103 patients, respectively. At least one conventional imaging (CI) as CT and/or MRI was performed for each one of the total patients. PET/CT studies revealed 66 true positive, 72 true negative, 4 false positive and 4 false negative results whereas the same values for CI were 65, 64, 4 and 6, respectively.

When all studies were analyzed on the basis of lesion for PET/CT, specificity was 94.7\%, and sensitivity being 94.2\%, where as corresponding values for conventional imaging methods were found $94.1 \%$ and $91.5 \%$ respectively. Recurrent lesions have been detected with PET/CT and treatment management was changed in 29 of 139 patients.

FDG-PET/CT improves the diagnostic accuracy in head and neck cancer patients.

\section{Key words}

PET/CT imaging, Head and neck cancers, Conventional imaging

\section{I ntroduction and objective}

PET is an imaging technique in which various biochemical and metabolical phenomenon is measured in vivo and visualized tomographically, by using positron-emitting radionucleotids. PET imaging aims to determine the distribution of radionucleotids within the body ${ }^{[1]}$. The most important difference of PET imaging in comparison to some other radiological methods lies in its being a functional imaging method. At functional imaging, it is possible to visualise tissue perfussion, glucose metabolism and receptor activities, by using appropriate methods and imaging agents ${ }^{[2]}$. Integrated 
PET/CT devices provide in a single examination both metabolic information by use of PET and anatomical information using CT.

18F-FDG delivers high-resolution tomographic images that are easily reachable, rapid and sensitive. Therefore PET has been proved to be a robust, strong imaging method in examining patients with various malignancies.

Compared to radiological imaging techniques such as ultrasonography, CT, MRI, PET as a molecular imaging technique, allows recognition of anomalities in early stages and before structural modifications take place according to conventional methods. PET is a non-invasive method allowing the whole body to be rapidly imaged. It does not get affected from metallic implants, and can be applied to patients with immune system deficiencies.

The role of PET/CT imaging is still controversial in head and neck cancers. The role of PET/CT in primary staging is not well established. According to National Comprehensive Cancer Network (NCCN) guidelines (version 1.2012), PET or PET/CT is recommended for stage III (T3, N0, M0, or T1-3N1M0) and stage IV (T1-T4, N0-N3, M0-M1) cancer because it may alter management by upstaging patients ${ }^{[3]}$.

We aimed to determine the effectiveness of the 18F-FDG PET/CT imaging technique for patients with head and neck cancers at staging and re-staging as well as to compare this method with the corresponding clinical and radiological methods.

\section{Materials and methods}

PET/CT examinations were retrospectively evaluated in a total of 139 patients (109 men, 30 female) with histopathologically proven squamous cell carcinoma of head and neck who were undergone PET/CT imaging for initial staging and restaging. All patients with blood sugar level $<140 \mathrm{mg} / \mathrm{dl}$ were fasted for 6 hours before mean $370 \mathrm{MBq}(10 \mathrm{mCi})$ 18F-FDG intravenous injection. Talking wasn't allowed during uptake phase to minimize the physiological muscle involvement in patients with head and neck cancer. Patients were kept at rest in a silent room and voided just before starting the acquisition to avoid urinary tract artifacts. Water is ingested before imaging to prevent saliva accumulation in the mouth and osephagus. Neither intravenous nor oral contrast is used for the reason to avoid radioactivity accumulation in the neck and oropharyngeal region. PET/CT scans were obtained 60 min. after injection using an integrated scanner (Siemens Biograph-6 Model HIRES PET/CT) from the skull to the upper thigh. Whole-body CT was performed before PET acquisition without intravenous contrast administration. PET acquisition was performed three minutes per 5-7 bed position.

When interpreting SUVmax, SUVmean and size criteria on PET fusion images were graded as benign: 0, unknown/ suspicious: 1 and malignant: 2 . Increased focal 18F-FDG uptake area corresponding to the abnormal CT is interpreted as malignant lesion. Increased 18F-FDG uptake at the normal anatomical structures (bladder, ureter, kidney, brown adipose tissue, etc.) was accepted as benign physiological uptake. The pathological findings on PET-CT images were confirmed with clinical follow-up notes (biochemical parameters and clinical information) and histopathological results. Mean duration of imaging for the 103 patients whom PET/CT has been applied for restaging after the treatment were $8 \pm 3$ weeks. At least one conventional imaging (CI) as CT and/or MRI was performed for each one of the patients.

In the current study, histopathology and follow-up information after PET/CT served as the standard of reference. For final assessment standards of references for lesions were based on biopsy, interval growth or reduction after chemotherapy.

\section{Statistical analysis}

- Data were analyzed using SPSS. Specificity, sensitivity, positive predictive value (PPV), negative predictive value (NPV), and accuracy were calculated with $95 \%$ confidence intervals and $p$ values $<.05$ were interpreted as 
significant results. Resolution and specificity regarding PET/CT and CI methods have been calculated separately once for the tumor localisations and once for the whole study.

- A false positive error, or in short false positive, commonly called a "false alarm", is a result that indicates a given condition has been fulfilled, when it actually has not been fulfilled.

- A false negative error, or in short false negative, is where a test result indicates that a condition failed, while it actually was successful, i.e., erroneously no effect has been assumed.

- Sensitivity: True positive/(True positive + False negative). The probability of the test's being positive when there is sickness.

- $\quad$ Specificity: True negative/(True negative + False positive). The probability of the test's being negative when there is no sickness.

- The positive and negative predictive values (PPV and NPV respectively) are the proportions of positive and negative results in statistics and diagnostic tests that are true positive and true negative results.

- $\quad \mathrm{PPV} \mathrm{TP} /(\mathrm{TP}+\mathrm{FP})$

- $\quad \mathrm{NPV}(\mathrm{TN} / \mathrm{TN}+\mathrm{FN})$

\section{Results}

A total of 139 patients (109 men, 30 female) with histopathologically proven squamous cell carcinoma of head and neck were undergone PET/CT imaging for initial staging and restaging included in this study. The mean age of the patients has been measured to be 57.3 (Range: 20-83 years). A total of 146 PET/CT imaging were performed in these patients. PET/CT imaging were performed for staging and restaging in 36 and 103 patients, respectively. In these 139 patients, the primary sites of cancer were as follows: 39 nasopharyngeal region, 25 oral cavity, 7 paranasal sinus, 52 laryngeal region, 1 mandibula, 1 hypopharyngeal region, 11 to be unidentified (see Table 1).

Table 1. Characteristics of patients with squamous cell head and neck carcinoma

\begin{tabular}{ll}
\hline Characteristic & Value \\
\hline Age & $20-83$ \\
Mean of age & 57.3 \\
Larynx & 52 \\
Nasopharyngeal & 39 \\
Oral cavity & 25 \\
Paranasal Sinus & 7 \\
Primary diagnose unidentifiable & 11 \\
Others (Ear, Hypopharynx) & 5 \\
\hline
\end{tabular}

Out of 36 patients staged initially, 34 have been identified to have primary tumor FDG uptake, and the mean SUVmax (maximum standardized uptake value) value thereof has been identified to be 9.5 .

Head and neck cancer recurrence were detected in 29 of the patients and treatment evaluation and approach accordingly held. 
PET/CT studies revealed 66 true positive, 72 true negative, 4 false positive and 4 false negative results whereas the same values for CI were 65, 64, 4 and 6, respectively (see Table 2 and 3). According to this study, considering the sampling of 146 cases, the PET/CT sensitivity, specificity and accuracy prove to be higher than those related to the CI.

Table 2. Study-based results

\begin{tabular}{llllllll}
\hline & TP & FN & TN & FP & Sensitivity (\%) & Spesificity (\%) & Accuracy (\%) \\
\hline PET/CT & 66 & 4 & 72 & 4 & 94.2 & 94.7 & 94.5 \\
CI & 65 & 6 & 64 & 4 & 91.5 & 94.1 & 92.8 \\
\hline
\end{tabular}

Table 3. Results according to primary lesion locations (Lesion-based)

\begin{tabular}{|c|c|c|c|c|}
\hline Localisation & $\mathbf{T P}$ & FN & $\mathbf{T N}$ & $\mathbf{F P}$ \\
\hline \multicolumn{5}{|l|}{ Laryngeal } \\
\hline PET/CT & 27 & 0 & 26 & 0 \\
\hline CI & 25 & 2 & 22 & 3 \\
\hline \multicolumn{5}{|c|}{ Nasopharyngeal } \\
\hline PET/CT & 18 & 2 & 20 & 0 \\
\hline CI & 16 & 1 & 20 & 2 \\
\hline \multicolumn{5}{|l|}{ Oral cavity } \\
\hline $\mathrm{PET} / \mathrm{CT}$ & 10 & 1 & 14 & 2 \\
\hline CI & 8 & 4 & 13 & 0 \\
\hline \multicolumn{5}{|c|}{ Paranasal Sinus } \\
\hline PET/CT & 2 & 1 & 4 & 1 \\
\hline CI & 3 & 0 & 4 & 0 \\
\hline \multicolumn{5}{|c|}{ Primary unidentifiable } \\
\hline $\mathrm{PET} / \mathrm{CT}$ & 8 & 1 & 2 & 0 \\
\hline CI & 7 & 0 & 3 & 1 \\
\hline \multicolumn{5}{|l|}{ Others } \\
\hline PET/CT & 4 & 1 & 2 & 0 \\
\hline CI & 3 & 1 & 1 & 0 \\
\hline
\end{tabular}

Sensitivity, specificity, positive and negative predictive values based on primary diagnosis using PET/CT and CI methods in comparison are shown in Table 4.

In our study we figured out the sensitivity of PET/CT to be $90.9 \%$ and NPV to be $94.1 \%$ for oral cavity tumors. Corresponding values for the CI techniques were $66.6 \%$ and $76.4 \%$ respectively. Regarding paranasal sinus tumors we found that PET/CT sensitivity was $66.6 \%$ and NPV was $83.3 \%$. Corresponding values for the CI techniques were $100 \%$ and $100 \%$ respectively.

For the larynx, nasopharynx, and unknown primary tumors, PET/CT sensitivity, specificity and PPV was higher than the conventional views, but for unknown primary tumor group, PET/CT NPV was $66.6 \%$ whereas CI, this value was calculated as $100 \%$. 
Table 4. PET/CT and Conventional Imaging methods in comparison based on primary diagnosis

\begin{tabular}{|c|c|c|c|}
\hline \multicolumn{3}{|l|}{ Conventional Imaging } & \multirow{2}{*}{$\begin{array}{l}\text { PET/CT } \\
100\end{array}$} \\
\hline \multirow{4}{*}{ Laryngeal } & Sensitivity \% & 92.5 & \\
\hline & Specificity \% & 88 & 100 \\
\hline & PPV \% & 89.2 & 100 \\
\hline & NPV \% & 91.6 & 100 \\
\hline \multirow{4}{*}{ Nasopharyngeal } & Sensitivity \% & 94.1 & 90 \\
\hline & Specificity \% & 90.9 & 100 \\
\hline & PPV \% & 88.8 & 90.9 \\
\hline & NPV \% & 95.2 & 95 \\
\hline \multirow{4}{*}{ Oral cavity } & Sensitivity \% & 66.6 & 90.9 \\
\hline & Specificity \% & 100 & 100 \\
\hline & PPV \% & 100 & 100 \\
\hline & NPV \% & 76.4 & 94.1 \\
\hline \multirow{4}{*}{ Paranasal Sinus } & Sensitivity \% & 100 & 66.6 \\
\hline & Specificity \% & 100 & 100 \\
\hline & PPV \% & 100 & 100 \\
\hline & NPV \% & 100 & 83.3 \\
\hline \multirow{4}{*}{ Primary unidentified } & Sensitivity \% & 100 & 88.8 \\
\hline & Specificity \% & 75 & 100 \\
\hline & PPV \% & 87.5 & 100 \\
\hline & NPV \% & 100 & 66.6 \\
\hline \multirow{4}{*}{$\begin{array}{l}\text { Others (Ear, Hypopharynx } \\
\text {..) }\end{array}$} & Sensitivity \% & 75 & 80 \\
\hline & Specificity \% & 100 & 100 \\
\hline & PPV \% & 100 & 100 \\
\hline & NPV \% & 50 & 66.6 \\
\hline
\end{tabular}

Out of 146 PET/CT restaging studies, 370 lesions have been identified. When all studies were to be analyzed on the basis of lesion for PET/CT, specificity was $94.7 \%$, and sensitivity being $94.2 \%$, where as corresponding values for CI methods were found $94.1 \%$ and $91.5 \%$ respectively. Recurrents have been detected with PET/CT and treatment management was changed in 29 of 139 patients. Figure 1, 2 and 3 illustrate PET/CT findings of three cases.

Figure 1. A 63 years old patient with laryngeal carcinoma. PET/CT images were performed for restaging. PET/CT images illustrate bilateral lung metastases (SUVmax 3.87), neck level 2a (SUVmax 7.59) and level 3 (SUVmax 5.38) metastasis.

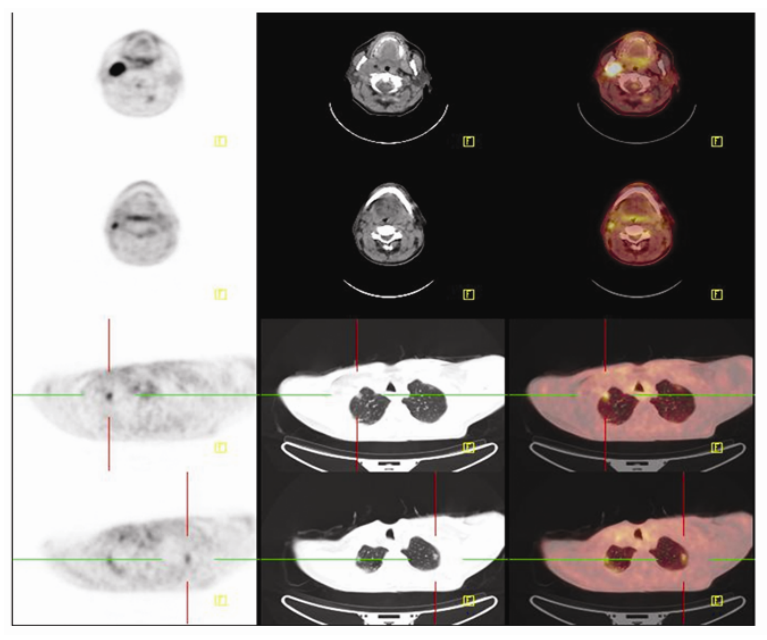


Figure 2. A 63 years old patient with nasopharyngeal carcinoma with lung and neck metastases. PET/CT images demonstrates mediastinal and neck (level 5a and $5 b)$ metastases.
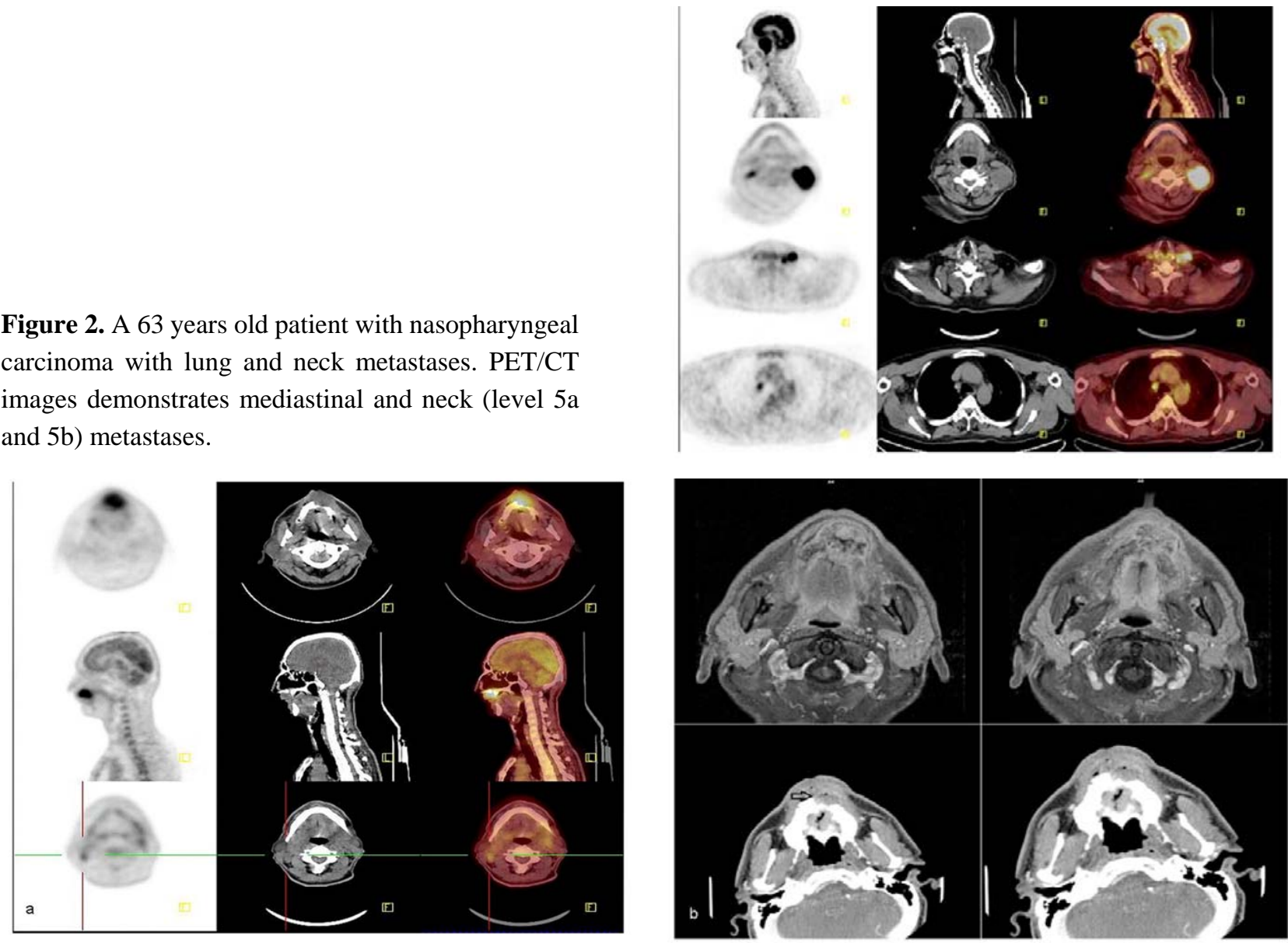

Figure 3. Initial staging of a 46 years old patient with paranasal sinus ca. FDG uptake can be seen in primary tumor and metastatic lymphadenopathy (a). Paranasal sinus MRI image of the same patient illustrates the primary lesion (b).

\section{Discussion}

Most of the head and neck carcinoma patients are initially diagnosed with cervical lymph node metastasis or local-regional advanced disease. The exact detection of cervical lymph node metastasis is very important for planning the margins of surgery and radiotheraphy. Although the role of FDG-PET in the recurrent head and neck carcinoma is established, there is no common concensus of the role at the initial staging. In the current study, out of 36 patients staged initially, 34 have been identified to have primary tumor FDG uptake, and the mean SUVmax (maximum standardized uptake value) value thereof has been identified to be 9.5. The sensitivity of FDG-PET was slightly superior than CI modalities at initial evaluation of cervical lymph node metastasis. The comparison studies showed that the sensitivity and specificity rates are $87 \%-90 \%$ and $80 \%-93 \%$ for FDG-PET, and $61 \%-97 \%$ and $21 \%-100 \%$ for CT-MRI ${ }^{[4]}$. In literature there are many propective and retrospective studies comparing PET or PET/CT with CI at both initial staging and restaging ${ }^{[5-22]}$. CI modalities are still the methods of choice for the evaluation of primary tumor in head and neck cancer patients. In a recent review article the major advantages of PET/CT over other imaging methods were ability of small lymph node metastases in difficult positions, detection of distant metastases and assessment of therapy response ${ }^{[23]}$. In the current study sensitivity and specificity rates were found to be $94.2 \%$ and $94.7 \%$ for FDG-PET/CT, and $91.5 \%$ and $94.1 \%$ for CT-MRI, respectively on lesion based analysis. FDG-PET/CT may prevent unnecessary neck dissection in some patients by detecting some important local regional metastasis. Additionally, PET-CT may also add information about advanced stage disease by detecting distant metastases. But for excluding false positive results, biopsy is recommended for PET positive regions. 
When we compared PET-CT and CI modalities according to tumor localisation; the highest sensitivity (100\%) and specificity (100\%) were found at larynx carcinomas, and the lowest were found at paranasal sinus carcinomas (66.6\%) for PET-CT. For CI techniques the highest specificity was $100 \%$ for paranasal carcinomas and unknown primary tumors, highest specificity was $100 \%$ for larynx carcinoma; and lowest sensitivity was $75 \%$ for others category and lowest sensitivity was $75 \%$ for unknown primary tumors. In paranasal carcinoma CI is the current standard imaging method. In a retrospective study including 21 patients with carcinoma in the sinus/nasal area and orbit by Wild $\mathrm{D}$ et al. ${ }^{[24]}$, the authors concluded that PET/CT adds clinically important information to CT or MRI, thus, influencing treatment. PET/CT was found useful for restaging but not for staging. According to our results it might be concluded that, PET-CT has higher sensitivity and specificity for laryngeal carcinomas, than CI modalities. In the other hand because of the limited number of patients with especially paranasal carcinoma and unknown primary, it would not be correct to conclude that CI modalities are more superior to PET/CT.

It has been reported that PET-CT has superior sensitivity and specificity for lymphatic node staging before RT ${ }^{[4]}$. FDG uptake was correlated with bad prognosis and higher recurrence rates ${ }^{[25]}$.

Sensitivity and specificity (86\% and 73\%) of FDG-PET was found higher than CT and/or MRI for the detection of residual or recurrent head and neck tumors after radiotherapy and/or chemotherapy ${ }^{[26]}$. The rate of false positive at forth month PET studies are less than the first month studies's performed after RT. Although there is no common concensus, it might be thought that the most appropriate time for treatment evaluation is 3-4 months after RT. When FDG-PET is compared with histopathological results for showing the residual tumor, one of the most important parameters was time interval between surgery and scan. As maximum effect of radiotherapy is seen at 3-4 months after therapy, higher sensitivity and negative predictive values are the time interval between PET and surgery must be kept as long as possible. Yao et al. found that FDG-PET has 100\% sensitivity and $80 \%$ specificity for detection residual tumor at 15 patients with residual lymphadenopathy 3-4 months after therapy ${ }^{[27]}$. Negative predictive value was found $97 \%$, positive predictive value was found $71 \%$ on another study that look for residual disease 8-12 weeks after chemoradiotherapy at 39 patients. PET study performed 3-4 months after therapy gives the patient a chance to be followed-up by high negative predictive value without any invasive procedure. As PET has relatively low positive predictive value, patients with positive results, must be histopatologically verified before performing any change at therapy regimen ${ }^{[28]}$. In the current study, the time interval between therapy (surgery, radiotherapy and chemotherapy) and PET-CT was $8 \pm 3$ weeks in 103 patients.

Negative predictive value was found between $66.6 \%$ and $100 \%$, when initial staging and re-staging patients were evaluated together. Highest NPV was 100\% for larynx carcinoma patients and $66.6 \%$ for unknown primary origin and other tumors group when we evaluate tumor according to the origin site. NPV for CI modalities was $100 \%$ for unknown primary and paranasal sinus tumors, and 50\% for others groups. CI modalities such as CT and MRI might cause false negative and positive results. In a systematic metaanalysis where PET and CT or MRI were compared, the sensitivity of FDG-PET was found 73\%-100\%, whereas CT and MRI were 25\%-100\%, and specificity were $57 \%-100 \%$ and $33 \%-100 \%$ respectively ${ }^{[1]}$. In a prospective study, the sensitivity of FDG-PET and CT-MRI were found $96 \%$ and $73 \%$, where specificity were $61 \%$ and $50 \%$, respectively ${ }^{[2]}$.

Adding FDG-PET to CI modalities is very beneficial at diagnosis of head and neck carcinoma patients. In the current study recurrence is detected at 29 patients, and change of therapy has been performed.

In the current study the small number of patients at different sites of head and neck tumors is one of the limitations. The other limitation was not to exclude nasopharyngeal cancer patients which has different clinical behavior. FDG-PET should be used for detection of primary tumor on patients with cervical lymph node metastasis whose primary tumor is not 
detected with diagnostic difficulties. FDG-PET should be used for evaluation of therapy response, where clinical evaluation is not efficient or suspicious.

\section{Conclusion}

The results of this retrospective study suggest that FDG-PET/CT improves the diagnostic accuracy in head and neck cancer patients and PET/CT is a useful adjunct to conventional imaging methods. It has the potential to improve the management of patients with head and neck cancer. Prospective studies that figure out concretely, using various algorithms, the effective usage of PET/CT on head and neck tumors (cancer) are believed to be needed. In the near future hybrid PET-MRI devices might be the first choice of use in the head and neck carcinoma, as they give optimum anatomical details.

\section{References}

[1] Menda Y, Graham MM. Update on 18F-fluorodeoxyglucose/positron emission tomography and positron emission tomography/computed tomography imaging of squamous head and neck cancers. Semin Nucl Med. 2005 Oct; 35(4): 214-9. PMid: 16150243. http://dx.doi.org/10.1053/j.semnuclmed.2005.05.001

[2] Vermeersch H, Loose D, Ham H, Otte A, Van de Wiele C. Nuclear medicine imaging for the assessment of primary and recurrent head and neck carcinoma using routinely available tracers. Eur J Nucl Med Mol Imaging. 2003 Dec; 30(12): 1689-700. Epub 2003 Oct 22. PMid: 14574516. http://dx.doi.org/10.1007/s00259-003-1345-4

[3] Flaming AJ Jr, Smith SP Jr, Paul CM, Hall NC, Daly BT, Agrawal A, et al. Impact of (18F)-2 fluorodeoxyglucose-positron emission tomography/computed tomography on previously untreated head and neck cancer patients. Laryngoscope 2007; 117: 1173-1179. PMid: 17603315. http://dx.doi.org/10.1097/MLG.0b013e31805d017b

[4] Blodgett TM, Ryan A, Brantetter B IV. Use of in the Evaluation of patients with Head and Neck Cancer. In: Richard L.Wahl. ed.Principles and Practise of PET and PET/CT. second edition. Philadelphia: Lipincott Williams \&Willkins, Wolters Kluwer. 2009; 221-240.

[5] Braams JW, Pruim J, Kole AC, Nikkels PG, Vaalburg W, Vermey A, et al. Detection of unknown primary head and neck tumors by positron emission tomography. Int J Oral Maxillofac Surg. 1997; 26: 112-115.

http://dx.doi.org/10.1016/S0901-5027(05)80829-X

[6] Laubenbacher C, Saumweber D, Wagner-Manslau C, Kau RJ, Herz M, Avril N, et al. Comparison of fluorine-18-fluorodeoxyglucose PET, MRI and endoscopy for staging head and neck squamous-cell carcinomas. J Nucl Med. 1995; 36: 1747-1757. PMid: 7562038.

[7] Adams S, Baum RP, Stuckensen T, Bitter K, Ho“ r G. Prospective comparison of 18F-FDG PET with conventional imaging modalities (CT, MRI, US) in lymph node staging of head and neck cancer. Eur J Nucl Med. 1998; 25: 1255-1260. PMid: 9724374. http://dx.doi.org/10.1007/s002590050293

[8] Stuckensen T, Kova'cs AF, Adams S, Baum RP. Staging of the neck in patients with oral cavity squamous cell carcinomas: a prospective comparison of PET, ultrasound, CT and MRI. J Craniomaxillofac Surg. 2000; 28: 319-324. PMid: 11465137. http://dx.doi.org/10.1054/jcms.2000.0172

[9] Kitagawa Y, Nishizawa S, Sano K, Ogasawara T, Nakamura M, Sadato N, et al. Prospective comparison of 18F-FDG PET with conventional imaging modalities (MRI, CT, and 67Ga scintigraphy) in assessment of combined intraarterial chemotherapy and radiotherapy for head and neck carcinoma. J Nucl Med. 2003; 44: 198-206. PMid: 12571209.

[10] Goerres GW, Schuknecht B, Schmid DT, Stoeckli SJ, Hany TF. Positron emission tomography/computed tomography for staging and restaging of head and neck cancer: comparison with positron emission tomography read together with contrast-enhanced computed tomography. Clin Imaging. 2008; 32: 431-437. PMid: 19006770.

http://dx.doi.org/10.1016/j.clinimag.2008.04.012 
[11] Andrade RS, Heron DE, Degirmenci B, Filho PA, Branstetter BF, Seethala RR, et al. Posttreatment assessment of response using FDG-PET/CT for patients treated with definitive radiation therapy for head and neck cancers. Int J Radiat Oncol Biol Phys. 2006; 65: 1315-1322. PMid: 16750327. http://dx.doi.org/10.1016/j.ijrobp.2006.03.015

[12] Rodrigues RS, Bozza FA, Christian PE, Koffman JM, Butterfield RI, Christensen CR, et al. Comparison of whole-body PET/CT, dedicated high-resolution head and neck PET/CT, and contrast-enhanced CT in preoperative staging of clinically M0 squamous cell carcinoma of the head and neck. J Nucl Med. 2009; 50: 1205-1213. PMid: 19617339. http://dx.doi.org/10.2967/jnumed.109.062075

[13] Ng SH, Chan SC, Liao CT, Chang JT, Ko SF, Wang HM, et al. Distant metastases and synchronous second primary tumors in patients with newly diagnosed oropharyngeal and hypopharyngeal carcinomas: evaluation of (18)F-FDG PET and extended-field multi-detector row CT. Neuroradiology. 2008; 50: 969-979. PMid: 18600319. http://dx.doi.org/10.1007/s00234-008-0426-2

[14] Seitz O, Chambron-Pinho N, Middendorp M, Sader R, Mack M, Vogl TJ, et al. 18F-Fluorodeoxyglucose-PET/CT to evaluate tumor, nodal disease, and gross tumor volume of oropharyngeal and oral cavity cancer: comparison with MR imaging and validation with surgical specimen. Neuroradiology. 2009; 51: 677-686. PMid: 19727695. http://dx.doi.org/10.1007/s00234-009-0586-8

[15] Yoon DY, Hwang HS, Chang SK, Rho YS, Ahn HY, JH Kim. CT, MR, US, 18F-FDG PET/CT, and their combined use for the assessment of cervical lymph node metastases in squamous cell carcinoma of the head and neck. Eur Radiol. 2009; 19: 634-642. PMid: 18843493. http://dx.doi.org/10.1007/s00330-008-1192-6

[16] Ghanooni R, Delpierre I, Magremanne M, Vervaet C, Dumarey N, Remmelink M, et al. 18F-FDG PET/CT and MRI in the follow-up of head and neck squamous cell carcinoma. Contrast Media Mol Imaging. 2011; 6: 260-266. PMid: 21861286.

[17] Gu DH, Yoon DY, Park CH, Chang SK, Lim KJ, Seo YL. CT, MR, (18)F-FDG PET/CT, and their combined use for the assessment of mandibular invasion by squamous cell carcinomas of the oral cavity. Acta Radiol. 2010; 51: 1111-1119. PMid: 20929295. http://dx.doi.org/10.3109/02841851.2010.520027

[18] Chan SC, Wang HM, Yen TC, Lin CY, Chin SC, Liao CT, et al. 18F-FDG PET/ CT and 3.0-T whole-body MRI for the detection of distant metastases and second primary tumours in patients with untreated oropharyngeal/ hypopharyngeal carcinoma: a comparative study. Eur J Nucl Med Mol Imaging. 2011; 38: 1607-1619. PMid: 21567252. http://dx.doi.org/10.1007/s00259-011-1824-y

[19] Ng SH, Chan SC, Yen TC, Liao CT, Lin CY, Tung-Chieh Chang J, et al. PET/CT and 3-T whole-body MRI in the detection of malignancy in treated oropharyngeal and hypopharyngeal carcinoma. Eur J Nucl Med Mol Imaging. 2011; 38: $996-1008$. PMid: 21327634. http://dx.doi.org/10.1007/s00259-011-1740-1

[20] Haerle SK, Strobel K, Ahmad N, Soltermann A, Schmid DT, Stoeckli SJ. Contrast-enhanced 18F-FDG-PET/CT for the assessment of necrotic lymph node metastases. Head Neck. 2011; 33: 324-329. PMid: 20652890.

[21] Stoeckli SJ, Haerle SK, Strobel K, Haile SR, Hany TF, Schuknecht B. Initial staging of the neck in head and neck squamous cell carcinoma: a comparison of CT, PET/CT, and ultrasound-guided fine-needle aspiration cytology. Head Neck. 2012; 34: 469-476. PMid: 21604319. http://dx.doi.org/10.1002/hed.21764

[22] Fakhry N, Michel J, Colavolpe C, Varoquaux A, Dessi P, Giovanni A. Screening for distant metastases before salvage surgery in patients with recurrent head and neck squamous cell carcinoma: a retrospective case series comparing thoraco-abdominal CT, positron emission tomography and abdominal ultrasound. Clin Otolaryngol. 2012; 37: 197-206. PMid: 22520870. http://dx.doi.org/10.1111/j.1749-4486.2012.02481.x

[23] Evangelista L, Cervino AR, Chondrogiannis S, Marzola MC, Maffione AM, Colletti PM, et al. Comparison between anatomical cross-sectional imaging and 18F-FDG PET/CT in the staging, restaging, treatment response, and long-term surveillance of squamous cell head and neck cancer: a systematic literature overview. Nuclear Medicine Communications. 2014, 35: 123-134. PMid: 24220055. http://dx.doi.org/10.1097/MNM.0000000000000022

[24] Wild D, Gerold K., Eyrich GK, Ciernik IF, Stoeckl SJ, Schuknecht B, et al. In-line 18F fluorodeoxyglucose positron emission tomography with computed tomography (PET/CT) in patients with carcinoma of the sinus/nasal area and orbit Journal of Cranio-Maxillofacial Surgery. 2006; 34: 9-16. PMid: 16343913. http://dx.doi.org/10.1016/j.jcms.2005.08.001 
[25] Schwartz DL, Ford E, Rajendran J, Yueh B, Coltrera MD, Virgin J, et al. FDG-PET/CT imaging for preradiotherapy staging of head-and-neck squamous cell carcinoma. Int J Radiat oncol Biol PHYS. 2005; 61(1): 129-36. PMid: 15629603.

http://dx.doi.org/10.1016/j.ijrobp.2004.03.040

[26] Allal AS, Slosman DO, Kebdani T, Allaoua M, Lehmann W, Dulguerov P. Prediction of outcome in head-and-neck cancer patients using the standardized uptake value of 2-[18F]fluoro-2-deoxy-D-glucose. Int J Radiat Oncol Biol Phys. 2004 Aug 1; 59(5): 1295-300. PMid: 15275712. http://dx.doi.org/10.1016/j.ijrobp.2003.12.039

[27] Nam SY, Lee SW, Im KC, Kim JS, Kim SY, Choi SH, et al. Early evaluation of the response to radiotherapy of patients with squamous cell carcinoma of the head and neck using 18FDG-PET. Oral Oncol. 2005 Apr; 41(4): 390-5. PMid: 15792611. http://dx.doi.org/10.1016/j.oraloncology.2004.10.005

[28] Porceddu SV, Jarmolowski E, Hicks RJ, Ware R, Weih L, Rischin D, et al. Utility of positron emission tomography for the detection of disease in residual neck nodes after (chemo) radiotherapy in head and neck cancer. Head Neck. 2005 Mar; 27(3): 175-81. PMid: 15627258. http://dx.doi.org/10.1002/hed.20130 